\title{
A reforma do Código Civil e os Princípios Gerais do Direito (*)
}

$\mathrm{Na}$ "Rivista Internazionale di Filosofia del Diritto", ano XVIII, fascículo $I$, se encontra um artigo de Grongio Del Vecchio, que, por seu grande interesse, data vênia, para aqui trasladamos quasi integralmente, traduzido pelo professor JORGE AMERICANO.

O novo Código Civil italiano, cuja aprovação em texto definitivo está próxima, assinalará sem dúvida um progresso em relação ao anterior. Disso dão segurança os longos estudos com os quais se procurou fixar na legislação italiana o espírito do novo tempo, mantendo íntegras as mais altas tradições da nossa ciência jurídica.

Os retoques em um organismo vivo, como é o organismo jurídico, são, todavia, de tal modo delicados e perigosos, que jamais será excessiva a prudência, antes de os realizar, especialmente quando se tratar de conceitos fundamentais. Não será inutil, neste momento, chamar a atenção para um retoque aparentemente leve, que parece em vias de sofrer o artigo 3.॰ das Disposições Preliminares. Como é sabido, o atual Código dispõe: " onde, todavia, o caso permaneça obscuro, decidir-se-á segundo os princípios gerais de direito" 0 Projeto definitivo traz, entretanto, a fórmula: "segundo os princípios gerais do direito vigente"

(*) Sobre o mesmo assunto, foi traduzida, pelo professor Cuovis Bevilaqua, a monografia de Giongio Del Vecchio "Sobre os principios Gerais do Direito". Veja-se, a propósito, a nota bibliográfica, de autoria do professor SPEncen VAMPRE, inserta na "Revista da Faculdade de Direito", volume 34, fasciculo I, página 373. 
Muitas são as incertezas sobre este ponto, e talvez ainda não hajam cessado. Na verdade, o Projeto do novo Código, da Real Comisssão (Presidente Vittorio Scialoja, vice-presidente Mariano D'Amelio), publicado em 1930, mantinha a fórmula do velho Código; e não indiferentemente, mas devido a razões precisas, indicadas no Relatório. "Na realidade não se pode negar", assim se exprimia rigorosamente o Relatório com referencia à fórmula atualmente em vigor (princípios gerais de direito), "que esta esteja redigida de modo a satisfazer às exigencias razoaveis da doutrina e a servir convenientemente à prática judiciária. "O mesmo Relatório recordava que Códigos recentes, como os do Brasil, Argentina e México, reproduziram literalmente a fórmula da legislação italiana". Após várias considerações concluia que "foi preferida a fórmula atual, por ser mais lata e compreensiva"

No mesmo sentido se exprimiram sucessivamente corporações de grande autoridade, tanto na Argentina, como nas Universidades Italianas. Apesar disso, e dizêmo-lo não sem alguma estranheza, viu-se que o Projéto definitivo, ha pouco publicado, substitue à fórmula atual a outra "princípios gerais do direito vigente" Com isto se supõe, segundo algumas opiniões, ef etivamente manifestadas, como se vê no Relatório, obviar ao perigo de interpretações errôneas. Mas não é dificil o fato de que, desde 1865 até hoje, nenhum inconveniente se verificou a este propósito na aplicação do atual Código; ao passo que iriamos ao encontro de reais perigos, si se tornasse definitiva a nova fórmula proposta.

Recordemos algumas noções elementares. A impossibilidade de preverem os Códigos e as leis in genere a todas as controvérsias futuras é reconhecida ad antiquo (tambem com fórmulas clássicas, pela jurisprudência romana) e não pode ser seriamente contestada. E' da natureza das coisas que o direito se desenvolva continuamente, em estreita conexão com o desenvolvimento do espírito e da vida, que é uma renovação perene. Daí deriva justamente o perpétub trabalho da jurisprudência, que não é somente a apli- 
cação mecânica de artigos de lei, mas o vivo "re-pensamento", a gestão fecunda e frequentamente uma verdadeira "re-creação", pela qual todo o organismo jurídico se enriquece e revigora. Sem isso, sem essa nova linfa continuamente trazida pelos próprios atos da prática judicial, as leis cairiam logo, como ramos sêcos.

Por outro lado, tambem é certíssimo que todas as controvérsias que surgem na vida social, dada a contraposição das exigências recíprocas, exigem solução jurídica. 0 juiz, por determinação do próprio legislador, jamais pode eximir-se de sentenciar, alegando a falta de norma legal. Si esta não lhe é dada pelo legislador, nem existe alguma que se aplique por analogia, deve achá-la o juiz. Onde? E' o problema que a fórmula em discussão visa resolver.

A solução correta, que pela jurisprudência romana fôra estabelecida com perfeita lógica, e que perdurou até as recentes instâncias de um positivismo estreito, é a seguinte: $O$ direito de um povo (jus in civitate positum) é a expressão particular de exigências universais da natureza humana; é, pois, a especificação de qualquer coisa mais geral e mais profunda. Donde, não bastam as formulações particulares, é preciso recorrer às raizes do sistema, as quais não são, entretanto, próprias só do sistema, porém são necessariamente comuns a todos os sistemas: pois, sendo uma a razão humana, uma será no seu princípio a lógica do direito (naturalis ratio). Assim, os Romanos, aos quais ninguem negaria alto e legítimo orgulho nacional, mesmo em matéria jurídica, e especialmente nela, não hesitaram em afirmar que todos os povos dirigidos por leis e costumes, "partim suo proprio, partim communi omnium hominum jure utuntur"; e assim, distinguiram no seu próprio direito, como no direito-de todos os outros povos, uma parte ligada a contingências particulares, e uma parte diretamente fundada na natureza comum a todos os povos. Não foi de modo diverso que Aristoteles distinguira o " $\nu \ell \mu o s ~ โ \delta \operatorname{cos"~do~}$ "vouos xouvós"

A referência aos "princípios gerais de direito" significa justamente o reconhecimento positivo deste conceito, o qud 
não implica de modo algum, como se supõe erradamente, na diminuição da autonomia nacional, mas, ao contrário, na sua mais alta e exata consagração.

E' absolutamente infundado o receio, que tambem já foi manifestado, de que possa ser entendida a fórmula "princípios gerais de direito" como referente a direitos estrangeiros, pois tal perigo está peremptoriamente excluido, além de outros argumentos, pelo próprio adjetivo "gerais", o qual significa exatamente que os princípios de que se trata devem compreender o direito italiano como o gênero compreende a espécie. $O$ fato de poderem ser, e serem virtulmente, estes princípios, pela sua própria generalidade, pertinentes tambem a qualquer outro sistema jurídico, em nada diminue, antes lhe acrescenta a importância e o significado para a nossa Nação; salvo si, por vaidade tola, considerar-se inferioridade para o indivíduo ou para o povo, o pertencer ao gênero humano.

A parte propriamente específica, a saber aquela em que se revela o genio peculiar a cada povo, é precisamente expressa nas suas leis e costumes; mas para adaptar o sistema a qualquer possivel caso imprevisto, não ha outra solução, onde as determinações positivas atingirem o seu limite, sinão recorrer ao fundamento do direito in genere, vale dizer, àquela ordem de princípios que descendem diretamente da natureza do espírito humano, uno na sua essência, mas sempre renovados.

E' excusada toda intromissão arbitrária de elementos heterogêneos no sistema jurídico nacional, pela invocação aos princípios gerais que estão na base do próprio sistema (si bem que não exclusivos dele), pois conduziria inevitavelmente à colisão com as normas vigentes, que permanecem inviolaveis em qualquer caso, sendo precisamente a insuficiência das normas positivamente estabelecidas para resolver a controvérsia, o pressuposto para a aplicação dos princípios gerais. E' bem certo, portanto, que os princípios gerais são e devem ser o meio de integração e de coerente 
desenvolvimento, nunca um meio de contradição. Confirma-o o fato, bastante eloquente, a saber, que sob o império do Código vigente, em mais de setenta anos nenhum inconveniente dessa espécie se verificou. Os magistrados italianos conhecem bem a lógica do sistema que são chamados a interpretar, e é fantasioso o temor de que dele se afastem para seguir direito estrangeiro.

$E^{\prime}$ tambem infundado o receio, que tambem às vezes foi expresso, de que a fórmula "princípios gerais de direito" signifique a re-exumação das teorias jus-naturalistas, no que teem de mais velho, o que vale dizer, um sistema abstrato de normas imutaveis, formuladas num misto de êrro e de verdade, por alguns autores dos séculos XVII e XVIII. Os erros por eles cometidos foram suficientemente dissipados pela moderna Filosofia do Direito, e ninguem pensa em os reviver. Isso não obsta a que ainda se possa falar em direito natural, no mais profundo e mais próprio sentido deste termo, isto é, em referência a uma suposta e inexistente natureza extra-social do homem, e tambem com referência às leis eternas do espírito e à estrutura própria da razão: leis e estrutura que se explicam tambem no direito e que, não só não excluem dele a vida, o movimento e o progresso, mas pelo contrário, os tornam possiveis e inteligiveis. A reta noção do direito natural jamais obstou ao desenvolvimento do direito positivo, e foi, até, em todas as épocas, o seu mais eficaz estímulo, o seu fermento mais fecundo. Seria facílimo dar exemplos disso. Basta lembrar que a contínua aproximação, operada sistematicamente pelos juristas romanos, entre o direito positivo e o seu fundamento natural (naturalis ratio) foi justamente o que conduziu o direito romano ao seu maravilhoso e incessante aperfeiçoamento. Bem observava MaINe (testemunho insuspeito, pois era mais historiador do que filósofo), que sem a crença dos juristas romanos na naturalis ratio como fundamento do direito, não se explicaria porque foi eminentemente progressista o direito romano, e não estacionário, como por exemplo o direito indú. 
E', pois, méra ilusão supor que baste a generalização das normas vigentes, por meio da analogia para descobrir os princípios gerais, o que justificaria a expressão "princípios gerais do direito vigente" A verdade é, antes de tudo, que somente é contempládo e querido pelo legislador o recurso aos princípios gerais para os casos que não possam ser decididos com base nas normas vigentes, nem por meio da analogia. Ademais, os lógicos demonstram que analogia não pode estender-se indefinidamente; portanto, querer ligar o intérprete a ela significaria tolher-lhe o meio de obter um reto critério para alguma controvérsia possivel, diversa dos casos previstos, quando a lei lhe impõe que o faça. Justamente uma das corporações interpeladas pelo Ministério de Justiça sobre o Projeto do novo Código (A Comissão Real dos Procuradores de Trieste e Capodistria), aprovando a fórmula já proposta pela Real Comissão, afirmava "a inoportunidade de limitar o alcance da referência aos princípios gerais de direito, com o acréscimo - vigente -, o qual não faria sinão falsear-lhe o conceito" Poder-se-iam aduzir no mesmo sentido ainda outras observações e confirmações autorizadas, que omitimos, por brevidade.

Exprimamos, portanto, o vóto de que, de acôrdo com o Código atual e com o primeiro Projeto de reforma, elaborado em pleno clima fascista, seja mantida, como mais própria e ampla, a fórmula "princípios gerais de direito"

$\mathrm{Si}$, entretanto, por preconceitos anti-filosóficos que em demasia dominam a mente de muitos juristas, vier a ser adotada a fórmula "princípios gerais do direito vigente", observemos que, tomada literalmente, ela poria fim ao natural progresso dos conceitos fundamentais da jurisprudência.

De fato, desde que a expressão "vigente", segundo tal opinião, deveria entender-se no sentido de "positivo", o resultado literal seria este: que em nenhum caso, nem mesmo nos casos não previstos pelas leis positivas, poder-se-ia ado- 
tar o critério mais alto e justo, deduzido das razões intrínsecas do direito, como são sentidas pela conciência social dos nossos tempos. Renunciar-se-ia àquele precioso e salutar subsídio que, para o são desenvolvimento do organismo jurídico, é constituido pelos chamados "conceitos válvulas" Ligaria as mãos do intérprete uma danosa compreensão, impedindo-o de dar satisfação adequada às mais vastas aspirações da nova conciência jurídica nacional. Isto no rigor dos termos. 